patients who had received no blood together with patients who had received less than five units. However, a retrospective analysis of 101 consecutive first cadaver renal allografts between 1968 and 1976 revealed the strikingly beneficial effects of prior blood transfusions. Forty-two patients were known never to have received a blood transfusion and only $20 \%$ of these grafts were functioning at one year. However, there were 28 patients who had received between one and six units of blood and $63 \%$ of these grafts were functioning at one year. Finally, 31 patients were known to have received more than six units and the oneyear graft survival in this group was $83^{\circ}{ }_{0}$. It is important to stress that all these patients were treated by the same team over the eight-year period and there had been no change in either surgical technique or immunosuppressive protocol.

Since July 1975 all patients awaiting a renal allograft have been deliberately transfused with single units of whole blood at monthly intervals until the patient has received a maximum of three units, but patients receive transplants, should a kidney become available, two weeks after the first unit of blood. Using this protocol, in the past $2 \frac{1}{2}$ years no graft has failed on account of rejection within the first 6 months of transplantation.

Further evidence has recently been presented by Opelz and Terasaki²; they reviewed 14 papers, all of which demonstrated the beneficial effect of blood transfusions.

We feel that the evidence is now so strong on this aspect of renal transplantation that information should be pooled with regard to the minimum amount of blood required for this protection and its timing with respect to subsequent transplantation.

B Hulme

M E SNELL

\section{Renal Unit,}

St Mary's Hospital,
London W2

'Pletka, P, et al, I.ancet, 1969, 1, 1 Opelz, G, and Terasaki, P I, Dialysis and Trans-
plantation, 1977, 6, 46.

\section{Psychological evaluation in cases of self- poisoning}

SIR,-The trial of assessment methods for patients admitted to hospital after selfpoisoning reported by $\mathrm{Dr} \mathrm{R}$ Gardner and his colleagues at Cambridge (17 December, p 1567) is salutary and of great importance, but I believe the main recommendation would be justifiable only if the results could be generalised. It was found that assessment by medical teams as to suicidal risk or need for social worker or psychiatric referral was as good as assessment made by psychiatrists when relapse at one year was examined. The authors suggest that the recommendation made by the Ministry of Health in 1968 that all such patients should be seen and assessed by psychiatrists should be amended. Medical teams were shown to have done the job just as well. The authors therefore suggest that with scarce specialist resources the time of psychiatrists could be used more effectively in other work. They point out that now one in seven of all acute medical admissions is for self-poisoning.

In this trial members of the seven medical teams who took part were given psychiatric instruction about the phenomena of selfpoisoning by the psychiatrist mainly con- cerned, were given literature to read, and provided with handouts. Nursing staff were also involved and contributed to the assessments, although how much prior instruction they received is not clear. What is clear is that those taking part in the trial knew they were in it and must have been highly motivated to do their best and to take a very responsible attitude to these patients. It may well be true, as the authors suggest, that unfavourable attitudes among consultants, junior doctors, and nurses to those who poison themselves have changed in the past 10 years. However, had the medical teams concerned not known they were in a trial and not received prior psychiatric instruction the results might have been very different.

I agree that it is highly desirable that junior medical staff and nurses should receive psychiatric instruction in this field, and already in the past 10 years undergraduate education in psychiatry has greatly improved. Before the recommendation to which the authors refer is amended I think it would be wise to ensure that those who are asked to take on this responsibility are given the knowledge and training necessary for it, and that they are motivated to accept it.

Institute of Psychiatry,

Denis Hill

\section{Transplacental hyponatraemia due to oxytocin}

SIR,-The report by Drs R H Schwartz and $\mathrm{R}$ W A Jones (2 January, p 152) emphasises a significant risk in the use of oxytocin for induction of labour. Although the risk can be overcome by the judicious use of the automatic infusion systems, those are not universally accepted and cases such as those described occur with an unacceptable frequency. A useful alternative which uses a minimum of infused fluid is with intravenous prostaglandin $\mathrm{E}_{2}$, since a 7-8-h labour may be conducted using $0.75 \mathrm{mg}$ in $500 \mathrm{ml}$ dextrose or Hartmann's solution, starting at 10 drops/ min and escalating to 20 drops/min after 30 min. I have employed this method of induction in several primigravidae, the majority of whom were hypertensive, and found that one rarely exceeds $20 \mathrm{drops} / \mathrm{min}$ and in practice a reduction of 5 or $10 \mathrm{drops} / \mathrm{min}$ is necessary. I feel that this system gives adequate oxytocic stimulation, has little effect on fluid and electrolyte values in the mother and fetus, and that the unwanted side effects of prostaglandin do not present a great problem.

Queen Elizabeth Hospital,

Peter I Silverstone

Gateshead, Tyne and Wear

SIR,-I read with interest the account by Drs R H Schwartz and R W A Jones of transplacental hyponatraemia with abnormal neurology and fits in a newborn infant (21 January, p 152). I would suggest, however, that the child's problems were caused by asphyxia during the mother's fit rather than by hyponatraemia.

Some years ago Dr Kate Chalmers and I measured cord blood sodium on 30 or 40 babies, most of whom had been born after induction with oxytocin in $5 \%$ dextrose. We found an almost linear relationship between plasma sodium and the quantity and duration of intravenous fluid given to the mother. A concentration of $120 \mathrm{mmol} / \mathrm{l}$ was not infrequent. Hyponatraemia is thus common among normal newborns-indeed, as common as medical induction.

Early in my career I looked after a baby born to a young woman who had been overtransfused with $5 \%$ dextrose solution and who subsequently died with a plasma sodium concentration of $106 \mathrm{mmol} / \mathrm{l}$. The baby was entirely asymptomatic in spite of also having a plasma sodium of $106 \mathrm{mmol} / 1$, which rose to normal levels in a few days with no treatment.

These two experiences have convinced me that, although hyponatraemia may accompany neurological problems in the newborn, there is no direct cause-and-effect relationship between the two, at any rate in otherwise normal babies.

Department of Paediatrics,

STEPHEN WARE

Southampton General Hospital Southampton

SIR,-We read with interest the report presented by Drs R H Schwartz and R W A Jones (21 January, $p$ 152). Within a period of 6 months we have had two similar cases at this hospital.

In a 26-year-old gravida 2, para 1 patient labour was induced at 42 weeks with oral prostaglandin $E_{2}$ followed by an intravenous infusion of oxytocin. During the $17 \mathrm{~h}$ of the labour she received 6.21 of $5 \%$ dextrose with no added electrolytes. The total urinary output during this time was 1.2511 . Thirty minutes after a spontaneous vaginal delivery she had a grand mal convulsion treated with intravenous diazepam. A provisional diagnosis of water intoxication was made, the plasma concentration of sodium being $120 \mathrm{mmol} / \mathrm{l}$. At birth the female infant was noted to be limp, with an Apgar score of 6 at one minute. At the age of $6 \mathrm{~h}$ she also had a generalised convulsion, the plasma sodium concentration being $116 \mathrm{mmol} / 1$.

In the second case a 26-year-old primigravid patient in whom labour was induced for postmaturity was given oral prostaglandin $E_{2}$ followed by an infusion of oxytocin. She was in labour for $18 \mathrm{~h}$, during which time she received 51 of fluid, 21 of which was dextrose saline and the remainder electrolyte-free fluid; the urine output was $600 \mathrm{ml}$. Because of the low output it was suspected that she was developing asymptomatic water intoxication and the plasma sodium concentration was found to be $121 \mathrm{mmol} / \mathrm{l}$ immediately post partum. Kielland's forceps rotation and delivery were performed for delay in the second stage of labour. The baby was symptomless, having an Apgar score of 9 at one minute, and the plasma sodium concentration was $125 \mathrm{mmol} / 1$.

In our experience water intoxication is a not uncommon complication when oxytocin is used for the induction of labour. However, it appears from the two cases described that when electrolytes are included in the intravenous infusion the fall in plasma sodium concentration is not as great and symptoms may thereby be prevented. It is of interest that oral prostaglandin was used in both these cases.

M F VERE

SUSAN M SELlERS

Department of Obstetrics and Gynaecology,

Department of Obstetrics and
Bristol

\section{Morale in mental handicap hospitals}

SIR,-Members of the Mental Health Group Committee of the BMA have asked me to write in support of Dr D A Spencer (7 January, p 44).

Ten points of concern are mentioned by 
Dr Spencer. They are centred in organisations whose intentions are good but whose efforts diminish the morale of those who work in mental handicap hospitals. Clinicians in general medicine and surgery do not have their efforts criticised by lay organisations to the extent that psychiatrists do. In the field of mental handicap hospitals the Department of Health and Social Security reiterates that public spending cuts will not apply. In spite of this, lay organisations, often critical of the work of psychiatrists and nurses, forecast the transfer of the care of mentally handicapped patients to psychologists and social workers working in centres in the community. Nothing is done by the DHSS to counter such criticism and its consequent depressing effect on those doctors and nurses who spend their lives looking after severely handicapped patients and who know that many of their charges could never survive outside hospital.

Mental handicap is one of the grey areas of medicine and workers in its hospitals need unqualified support. In the past this was provided by loyal management committees and regional hospital boards. Since reorganisation single mental handicap hospitals find themselves isolated in the management sphere of area health authorities which are not always sympathetic and which have to be reminded frequently of the exemption from spending cuts. Perhaps the DHSS could think more positively of its responsibility for the mental handicap hospitals and provide them with the leadership they need.

\section{JOHN T HUTCHINSON}

Mental Health Group Committee, BMA St Giles's Hospital,

London SE5

\section{Help for parents after stillbirth}

SIR,-Further suggestions are requested by Professor R W Beard and his colleagues (21 January, $p$ 172). It has been my experience that parents blame not only themselves but, more destructively, each other. This should be made more explicit. Often this anger presents in loss of libido in either partner, a symptom also of loss of sexual self-esteem. Some mention of this could prevent secondary misinterpretation by the partners. A more definite warning that a further pregnancy should not be seen as a replacement baby (often an ill-advised suggestion by doctors or friends) should be given priority in counselling.

As a corollary to the increasing awareness of the psychological disturbance related to stillbirth could some thought also be given to the similar problems often experienced with a late miscarriage? These women are even less likely to receive professional help, as they are rarely followed up by gynaecologists and do not qualify for statutory visits from midwives, while society views the event as of minor significance.

DOROTHY BLACK

University Department of Psychiatry,

Whiteley Wood Clinic, Sheffied

SIR,-I read with interest the letter from Professor R W Beard and his colleagues (21 January, $p$ 172) and their proposals to distribute a leaflet to parents who have experienced the birth of a stillborn child.

The comprehensive nature of this leaflet is very impressive. My only reservation about it concerns the time at which it is to be given to parents. Since it suggests that the parents see and hold their baby it would appear that the leaflet is to be given to parents as soon as the baby is born. I feel that in the period immediately following the birth the parents are bound to feel shocked and certainly unable to take in such a mass of literature. Surely the suggestion that the baby be held by them would be better put gently to them by the medical or nursing staff present.

Subsequently discussion about stillbirth could be encouraged at a personal level between the ward staff and parents before the mother is discharged from hospital. It would seem important that all these parents should be visited by the health visitor at a point when the midwife has finished visiting; so often this is the time when their grief is most acute. I suggest that this leaflet should be given to the parents by the health visitor when she feels it to be appropriate and when the parents know that she will be visiting again, should they wish to discuss any matters arising from its contents.

As a health visitor working in a department of medical genetics I frequently have contact with parents who have had one or more stillborn babies. Many of them express feelings of isolation and an inability to discuss their situation with relatives and friends. I am therefore pleased that those concerned professionally with these patients are becoming more involved with this aspect of patient care. I am sure that the proposed leaflet would be very helpful to doctors, nurses, health visitors, social workers, and clergymen and would help to increase their insight into the many conflicting feelings that parents experience at this point of crisis in their lives.

MARY WEETMAN University Department of Medical Genetics, St Mary's Hospital, Manchester

\section{Contamination of surgical gloves}

SIR,-It has long been accepted that the use of talc as a surgical-glove powder can result in postoperative peritoneal adhesions as well as granulomata at the site of operation. Consequently starch powder has been used for the past 20 years in place of talc, although concern has been expressed in the medical literature that a similar granulomatous reaction is produced by this material. We have shown recently, however, ${ }^{2}$ ' that samples of surgeon's gloves manufactured during the $1972-5$ period have been contaminated with talc. Furthermore, tissue histologically classified as starch granulomata and showing the classical rounded starch particles with Maltese-cross birefringence was shown to contain talc. The analyses were undertaken using the highly sophisticated electron microscope microanalyser (EMMA-4, AEI) and it was obvious that only such procedures would localise and identify these extremely small particles which contaminated the gloves. At that time glove-manufacturing processes were probably ineffective in preventing access of talc, but continued quality control by these laboratories of subsequent batches of gloves has indicated that the major British manufacturer has been able to eliminate the problem and such gloves produced in the $\mathrm{UK}$ are uncontaminated.

It was stated then ${ }^{1}$ that certain samples of American-produced gloves which were investigated were heavily contaminated with talc. More extensive investigations have confirmed these earlier observations, clearly indicating that talc contamination of the American gloves is a common occurrence, with sometimes as much as $6 \times 10^{7}$ particles $/ \mathrm{cm}^{2}$ surface area. Furthermore, some samples were heavily contaminated with a diatomaceous material, shown in the accompanying figure together with the typical spectral analysis indicating the siliceous nature of the powder.
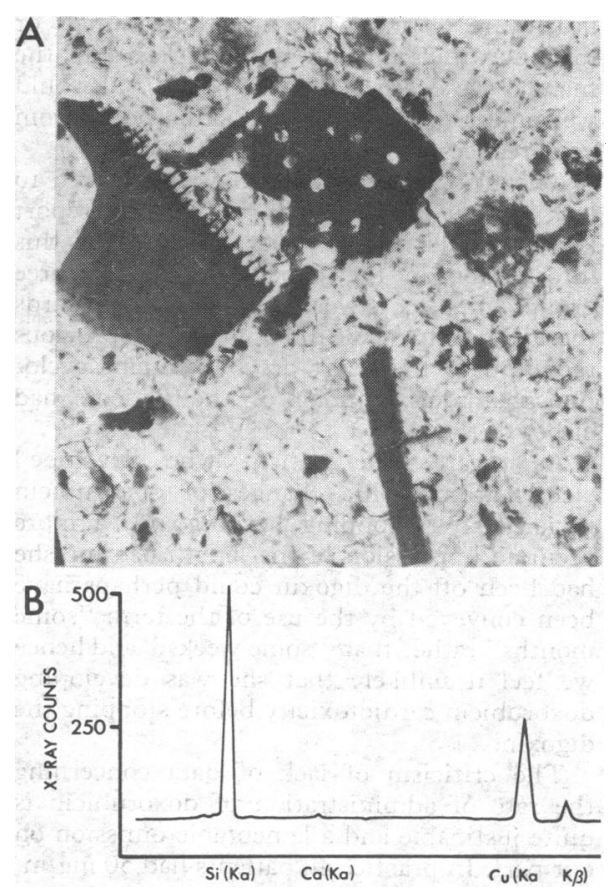

(A) Typical diatomaceous particles recovered from the surface of surgical gloves ( 55780 ) (B) spectral analysis from EMMA-4 showing the high silicon content of the particles. The copper peaks $(K \alpha$ and $K \beta)$ relate to the
em grid.

It is obvious that more careful control is necessary of the available procedures for the quality control of the materials used in the manufacturing processes concerned in surgical glove production. Since some of these American gloves are now available on the British market, care should be taken by the medical profession in their particular choice.

W J HENDERSON

A V MASKELL

K GRIFFITHS

Tenovus Institute for Cancer Research, Welsh National School of Medicine

W T BARR

Department of Pathology,

University Hospital of Wales, Cardiff

Henderson, W J, et al, Lancet, 1975, 1, 1419. Henderson, $W$ J, et al, British fournal of Surgery,

Doxorubicin cardiotoxicity: role of digoxin in prevention

SIR,-We would like to reply to the various criticisms made by $\mathrm{Dr} C \mathrm{~J}$ Williams (21 January, $p$ 176) in relation to our recent article (3 December, $p$ 1447).

In his letter Dr Williams states that "evidence on the protective effects of digoxin given before doxorubicin in animal models is conflicting."1-3 It is unfortunate that none of the three references cited makes any mention of the use of digoxin given before doxorubicin in order to prevent cardiomyopathy in animals. 